Received: 20 September 2017

Accepted: 27 March 2018

Published online: 12 April 2018
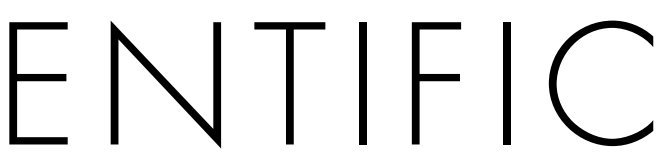

REP

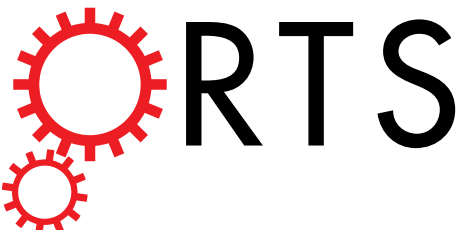

\title{
OPEN Affective and cognitive rather than somatic symptoms of depression predict 3-year mortality in patients on chronic hemodialysis
}

Hui-Teng Cheng $\mathbb{D}^{1}$, Miao-Chun Ho ${ }^{2}$ \& Kuan-Yu Hung ${ }^{1}$

Depression is more common in many medical conditions than among the general population and is associated with an increased risk of mortality. We aimed to determine whether somatic symptoms of depression were more predictive of mortality than affective and cognitive symptoms in hemodialysis patients. We conducted a prospective cohort study in which the survival outcomes of 151 subjects were followed for more than 3 years. Depression was assessed with the Taiwanese Depression Questionnaire (TDQ). Subjects with TDQ scores 19-54 (correlated with clinically significant depressive symptoms) and those with scores 15-18 had higher 3-year mortality rates than the two groups with lower scores $(40.0 \%, 46.7 \%, 16.0 \%$ and $19.6 \%, p=0.021$, ANOVA). Affective and cognitive symptoms, including sadness, tenseness, indecisiveness and low self-confidence, and one somatic item (bodily discomfort) were associated with mortality. Affective and cognitive symptoms affected quality of life more than somatic symptoms. The somatic subscale was associated with female gender, low income and education, dialysis vintage, and low serum creatinine and albumin levels, whereas the affective and cognitive subscale was associated with less education and a low serum albumin level. In conclusion, affective and cognitive symptoms of depression may better predict long-term mortality in patients undergoing chronic hemodialysis than somatic symptoms.

Depression is a mood disorder with a prevalence in the general population ranging from $1.6 \%$ in $\mathrm{China}^{1}$ to $5.0 \%$ in the United Kingdom ${ }^{2}$ and $9.0 \%$ in the United States ${ }^{3}$. Depression is even more common in patients with certain organic illnesses, such as congestive heart failure $(63 \%)^{4}$, malignancy $(20.7 \%)^{5}$ and diabetes $(20-25 \%)^{6}$. Coexistence of the diseases with depression is associated with many adverse outcomes, including increased mortality ${ }^{4,6,7}$. Depression is also very common in patients with end-stage renal disease who are undergoing hemodialysis, with prevalence rates ranging from $5 \%$ to $64.5 \%{ }^{8}$. Numerous studies have shown an association between depression and higher mortality rates in hemodialysis patients ${ }^{9-12}$, with few exceptions ${ }^{13,14}$. Depression is also associated with a poor quality of life $\mathrm{e}^{15-17}$.

The symptomatology of depression includes somatic complaints and non-somatic disturbance; the latter includes affective and cognitive impairments, such as sadness, negative thoughts, anhedonia or loss of interest, indecisiveness and suicidal ideation ${ }^{18}$. Somatic symptoms of depression include fatigue, poor appetite, concentration difficulty, bodily discomfort, poor memory or forgetfulness and loss of sexual drive ${ }^{19}$. The somatic symptoms of depression overlap with a variety of other disorders that may be present in patients on dialysis, such as hyperuremia $^{20}$ and sleep disorders ${ }^{21,22}$. In order to make a definite diagnosis of depression, low mood or decreased interest must be present. Otherwise, somatic symptoms such as fatigue, poor appetite and forgetfulness may be caused by inadequate dialysis or dementia ${ }^{23}$. The severity of somatic symptoms has been shown to be a better predictor of mortality than affective and cognitive symptoms in patients with myocardial infarction. In these patients, it is thought that somatic symptoms directly reflect physiological conditions ${ }^{24}$. However, the comparison has not been performed for other types of diseases.

${ }^{1}$ Division of Nephrology, Department of Internal Medicine, National Taiwan University Hospital, Hsin-Chu Branch, Hsin Chu City, Taiwan. ${ }^{2}$ Department of Nursing, National Taiwan University Hospital, Hsin-Chu Branch, Hsin Chu City, Taiwan. Correspondence and requests for materials should be addressed to H.-T.C. (email: hcheng@wustl.edu) or K.-Y.H. (email: kyhung@ntu.edu.tw) 
For hemodialysis patients, Kimmel et al. demonstrated an association between mortality and the Cognitive Depression Index (CDI), which is a 15-question subscale of the 21-question Beck Depression Inventory (BDI) that excludes items related to somatic symptoms ${ }^{25}$. In another smaller series that included patients undergoing hemodialysis and peritoneal dialysis, Peterson et al. showed an association between higher CDI scores and lower survival rates ${ }^{26}$. Kellerman et al. also demonstrated this association in patients with chronic kidney disease before entering dialysis ${ }^{27}$. To the best of our knowledge, there is no literature examining the association between somatic symptoms of depression and mortality in patients on chronic hemodialysis. In addition, if such an association exists, whether somatic symptoms are a better predictor of mortality than the affective and cognitive symptoms remains to be determined.

To answer these two questions, we conducted a prospective cohort study to determine how depressive symptoms affected 3-year mortality and quality of life, as the primary and secondary outcomes, respectively. We used the Taiwan Depression Questionnaire to measure the degree of various somatic, affective and cognitive symptoms. The questionnaire is similar to the commonly used Beck Depression Inventory, but has been adapted to be culturally relevant ${ }^{28}$. The classification between somatic and affective/cognitive items is largely based on the Cognitive Depression Index, a 15-item subscale that is included within the 21-item Beck Depression Inventory ${ }^{25}$. We also investigated the associations between the depressive symptoms and various demographic and biochemical parameters.

\title{
Results
}

Depressive symptoms are associated with higher mortality rates, lower quality of life, and low serum creatinine and serum albumin levels in patients on dialysis. In the current cohort, $43 \%$ of the subjects had scores higher than 19 , regarded as having depression ${ }^{28}$. These subjects had higher 3-year mortality rates than the patients with normal scores $(40.0 \%$ versus $23.3 \%$, Table 1$)$. Remarkably, a higher mortality rate was found in subjects with the Taiwanese Depression Questionnaire (TDQ) scores higher than 15 (Table 2). Patients with higher TDQ scores also reported a significantly poorer quality of life (Tables 1 and 2). The subjects with the highest TDQ scores $(>19)$ had lower serum creatinine and albumin levels than those with normal TDQ scores (0-8) (Table 2).

\begin{abstract}
Affective and cognitive symptoms of depression are better predictors of long-term mortality than somatic symptoms in patients on chronic hemodialysis. Only question 17 in the somatic subscale (bodily discomfort) showed a significant odds ratio for mortality. Conversely, many questions in the affective and cognitive subscale (i.e., 2, 7, 12,13 and 14) were associated with mortality. Those questions with significant hazard ratios of mortality were the same ones with significant odds ratios (Table 3). Kaplan-Meier survival analysis identified questions 17 (somatic), 2, 7, 12, 1315 and 18 (affective/cognitive) as associated with mortality (Table 3 and Fig. 1). The top four questions with the highest information values in prediction to mortality were questions 13, 7, 12 and 2 (Fig. 2). These questions were also the affective and cognitive questions that showed statistical significance in all three of the aforementioned analyses (Table 3).
\end{abstract}

Affective and cognitive symptoms of depression are more closely associated with lower quality of life than somatic symptoms of depression. When ranked according to the Spearman's rank order correlation coefficient (rho), affective/cognitive symptoms were more significantly correlated with lower quality of life, as compared to somatic symptoms ( $p<0.05$, Mann-Whitney U test; Table 4$)$. In other words, the questions with higher correlation coefficients were primarily regarding affective/cognitive symptoms.

Affective and cognitive symptoms of depression are associated with distinct demographic and biochemical characteristics as compared to somatic symptoms of depression. When comparing somatic and affective/cognitive subscale scores based on different demographic characteristics (Table 5), women appeared to have higher somatic scores $(\mathrm{p}=0.011)$ and affective/cognitive scores $(\mathrm{p}=0.051)$ than men. Less education was also associated with higher somatic and affective/cognitive scores. A lower income appeared to be a risk factor for a high somatic subscale score $(\mathrm{p}=0.019)$ but not for the affective/cognitive subscale score $(\mathrm{p}=0.179)$. When correlating subscale scores and the biochemical parameters (Table 6), we found that the somatic subscale score was significantly correlated with low creatinine, albumin and blood urea nitrogen (BUN) levels, as well as with age and the dialysis vintage. The affective/cognitive subscale score was significantly correlated with low creatinine, albumin, BUN and phosphate levels but not with age $(\mathrm{p}=0.248)$ or the dialysis vintage $(p=0.097)$. According to multiple linear regression to identify the important independent association factors (Table 7), somatic symptoms were associated with low serum creatinine and albumin levels and the dialysis vintage, whereas affective/cognitive symptoms were associated with a low albumin level.

\section{Discussion}

There are 4 major findings in this article. First, in dialysis patients, depressive symptoms are associated with mortality, even in patients who have elevated, but subthreshold scores on the TDQ.

Second, affective and cognitive symptoms, including sad mood (Q2), tenseness (Q7), indecisiveness (Q12), and low self-confidence (Q13), rather than somatic symptoms, predicted long-term mortality rates. Third, affective and cognitive symptoms were more correlated with quality of life than somatic symptoms. Fourth, distinct demographic and biochemical characteristics are associated with affective and cognitive symptoms of depression as compared to somatic symptoms of depression. The association factors for the affective and cognitive symptoms included lower education and serum albumin levels, while the somatic symptoms were associated with female gender, lower education level, lower income, low serum creatinine and albumin levels and dialysis vintage.

The finding that subthreshold depressive symptoms are also associated with higher mortality rate is important and has not previously reported, to our knowledge. All previous studies that have demonstrated the link between 


\begin{tabular}{|c|c|c|c|c|}
\hline & Total $(n=151)$ & $\begin{array}{l}\text { No depression (TDQ 0-18) } \\
(\mathbf{n}=\mathbf{8 6}, \mathbf{5 7 . 0 \% )}\end{array}$ & $\begin{array}{l}\text { Depression (TDQ 19-54) } \\
(\mathrm{n}=65,43.0 \%)\end{array}$ & $\begin{array}{l}p \text { value of } t \text {-test, z-test or } \\
\text { Fisher's exact test }\end{array}$ \\
\hline 3-year mortality & $46(30.5 \%)$ & $20(23.3 \%)$ & $26(40.0 \%)$ & 0.027 \\
\hline Age & $64.6 \pm 13.9$ & $63.5 \pm 14.2$ & $66.1 \pm 13.5$ & 0.984 \\
\hline Gender (woman \%) & $77(50.1 \%)$ & $39(45.3 \%)$ & $38(58.5 \%)$ & 0.109 \\
\hline Quality of life score & $79.87 \pm 16.29$ & $89.6 \pm 12.83$ & $66.9 \pm 10.21$ & 0.058 \\
\hline$\%$ QOL score $\leq 65$ & $30(19.9 \%)$ & $2(2.3 \%)$ & $28(43.1 \%)$ & 0.000 \\
\hline Marital status & & & & 0.752 \\
\hline married & $118(78.1 \%)$ & $68(79.1 \%)$ & $50(76.9 \%)$ & \\
\hline other & $33(21.9 \%)$ & $18(20.9 \%)$ & $15(23.1 \%)$ & \\
\hline Education & & & & 0.073 \\
\hline$\leq 6$ years & $85(56.3 \%)$ & $43(50.0 \%)$ & $42(64.6 \%)$ & \\
\hline$>6$ years & $66(43.7 \%)$ & $43(50.0 \%)$ & $23(35.4 \%)$ & \\
\hline Occupation & & & & 0.115 \\
\hline unemployed & $132(87.4 \%)$ & $72(83.7 \%)$ & $60(92.3 \%)$ & \\
\hline employed & $19(12.6 \%)$ & $14(16.3 \%)$ & $5(7.7 \%)$ & \\
\hline Religion & & & & 0.558 \\
\hline nil & $49(32.5 \%)$ & $26(30.2 \%)$ & $23(35.4 \%)$ & \\
\hline Buddhism & $65(43.0 \%)$ & $39(45.3 \%)$ & $26(40.0 \%)$ & \\
\hline Christianity & $3(2.0 \%)$ & $2(2.3 \%)$ & $1(1.5 \%)$ & \\
\hline Catholicism & $12(7.9 \%)$ & $5(5.8 \%)$ & $7(10.8 \%)$ & \\
\hline Taoism & $21(13.9 \%)$ & $14(16.3 \%)$ & $7(10.8 \%)$ & \\
\hline miscellaneous & $1(0.7 \%)$ & $0(0.0 \%)$ & $1(1.5 \%)$ & \\
\hline Monthly income (USD) & & & & 0.256 \\
\hline$<300$ & $87(57.6 \%)$ & $46(53.5 \%)$ & $41(63.1 \%)$ & \\
\hline $300-1000$ & $37(24.5 \%)$ & $20(23.3 \%)$ & $17(26.2 \%)$ & \\
\hline $1000-2000$ & $17(11.3 \%)$ & $13(15.1 \%)$ & $4(6.2 \%)$ & \\
\hline$>2000$ & $10(6.6 \%)$ & $7(8.1 \%)$ & $3(4.6 \%)$ & \\
\hline Living & & & & 0.990 \\
\hline alone & $5(3.3 \%)$ & $3(3.5 \%)$ & $2(3.1 \%)$ & \\
\hline with family & $139(92.1 \%)$ & $79(91.9 \%)$ & $60(92.3 \%)$ & \\
\hline other & $7(4.6 \%)$ & $4(4.7 \%)$ & $3(4.6 \%)$ & \\
\hline Diabetes mellitus & $84(55.6 \%)$ & $49(57.0 \%)$ & $35(53.8 \%)$ & 0.704 \\
\hline $\mathrm{BUN}(\mathrm{mg} / \mathrm{dL})$ & $75.2 \pm 20.9$ & $78.7 \pm 20.4$ & $70.9 \pm 21.1$ & 0.692 \\
\hline Creatinine (mg/dL) & $10.34 \pm 2.58$ & $10.90 \pm 2.5$ & $9.70 \pm 2.50$ & 0.968 \\
\hline Sodium $(\mathrm{mmol} / \mathrm{L})$ & $136.9 \pm 4.1$ & $137.2 \pm 3.5$ & $136.5 \pm 4.8$ & 0.015 \\
\hline Potassium $(\mathrm{mmol} / \mathrm{L})$ & $4.44 \pm 0.97$ & $4.51 \pm 0.84$ & $4.35 \pm 1.11$ & 0.641 \\
\hline Calcium $(\mathrm{mg} / \mathrm{dL})$ & $9.30 \pm 0.87$ & $9.26 \pm 0.87$ & $9.36 \pm 0.87$ & 0.561 \\
\hline Phosphate (mg/dL) & $4.90 \pm 1.47$ & $5.18 \pm 1.46$ & $4.52 \pm 1.40$ & 0.747 \\
\hline Ca $\mathrm{P}$ p product & $45.70 \pm 14.65$ & $48.00 \pm 14.30$ & $42.66 \pm 14.66$ & 0.573 \\
\hline Albumin (g/dL) & $3.65 \pm 0.37$ & $3.73 \pm 0.36$ & $3.53 \pm 0.35$ & 0.772 \\
\hline Glucose (mg/dL) & $153.2 \pm 65.8$ & $152.2 \pm 59.7$ & $154.5 \pm 73.5$ & 0.458 \\
\hline GOT (IU/L) & $18.4 \pm 10.1$ & $18.7 \pm 11.2$ & $18.2 \pm 8.5$ & 0.676 \\
\hline GPT (IU/L) & $19.1 \pm 20.0$ & $19.4 \pm 23.1$ & $18.8 \pm 15.1$ & 0.769 \\
\hline $\mathrm{Kt} / \mathrm{V}$ of urea & $1.34 \pm 0.22$ & $1.37 \pm 0.23$ & $1.30 \pm 0.20$ & 0.921 \\
\hline Dialysis vintage (years) & $4.5 \pm 3.9$ & $4.5 \pm 3.8$ & $4.7 \pm 4.1$ & 0.556 \\
\hline $\operatorname{ALKP}(\mathrm{U} / \mathrm{L})$ & $307.6 \pm 138.6$ & $309.2 \pm 146.5$ & $305.6 \pm 128.4$ & 0.704 \\
\hline Triglyceride $(\mathrm{mg} / \mathrm{dL})$ & $169.8 \pm 111.9$ & $164.8 \pm 98.5$ & $176.3 \pm 128.1$ & 0.348 \\
\hline Cholesterol (mg/dL) & $159.8 \pm 34.9$ & $159.9 \pm 36.3$ & $159.7 \pm 33.2$ & 0.461 \\
\hline Ferritin $(\mathrm{ng} / \mathrm{mL})$ & $460.8 \pm 444.5$ & $475.4 \pm 554.2$ & $441.4 \pm 233.5$ & 0.341 \\
\hline i-parathyroid hormone $(\mathrm{pg} / \mathrm{mL})$ & $338.0 \pm 271.4$ & $361.7 \pm 289.5$ & $306.7 \pm 244.0$ & 0.512 \\
\hline Hemoglobin $(\mathrm{g} / \mathrm{dL})$ & $10.78 \pm 1.51$ & $10.78 \pm 1.53$ & $10.78 \pm 1.50$ & 0.844 \\
\hline Platelet $(\mathrm{k} / \mu \mathrm{L})$ & $177.1 \pm 64.9$ & $176.9 \pm 59.8$ & $177.3 \pm 71.6$ & 0.676 \\
\hline
\end{tabular}

Table 1. Demographic and biochemistry characteristics of depressed and non-depressed subjects based on the Taiwanese Depression Questionnaire (TDQ) score $(\mathrm{n}=151)$. Data are presented as the mean \pm standard deviation, or the count number (percentage). The $\mathrm{p}$ values are from the analyses between the participants with and without depression. ALKP: alkaline phosphatase, BUN: blood urea nitrogen, Ca $\mathrm{x}$ P: calcium and phosphate product, GOT: glutamic oxaloacetic transaminase, GPT: glutamic pyruvic transaminase, i-parathyroid hormone: intact parathyroid hormone, Kt/V: dialysis adequacy by dialyzer clearance of urea $(\mathrm{K})$ times time $(\mathrm{t})$ divided by volume $(\mathrm{V})$ of the urea distribution, USD: US dollars. 


\begin{tabular}{|c|c|c|c|c|c|c|}
\hline Variables & Total $(n=151)$ & $\begin{array}{l}\text { (1) TDQ 0-8 } \\
(\mathrm{n}=46,30.5 \%)\end{array}$ & $\begin{array}{l}\text { (2) TDQ 9-14 } \\
(\mathrm{n}=25,16.6 \%)\end{array}$ & $\begin{array}{l}\text { (3) TDQ 15-18 } \\
(\mathrm{n}=15,9.9 \%)\end{array}$ & $\begin{array}{l}\text { (4) TDQ 19-54 } \\
(\mathrm{n}=65,43.0 \%)\end{array}$ & $p$ value \\
\hline 3-year mortality & $46(30.5 \%)$ & $9(19.6 \%)$ & $4(16.0 \%)$ & $7(46.7 \%)$ & $26(40.0 \%)$ & $\begin{array}{l}\mathbf{0 . 0 2 1} \\
(1)<(3) \\
(2)<(3) \\
(1)<(4) \\
(2)<(4)\end{array}$ \\
\hline Age & $64.6 \pm 13.9$ & $60.3 \pm 14.4$ & $63.2 \pm 13.5$ & $73.9 \pm 9.5$ & $66.1 \pm 13.5$ & $\begin{array}{l}0.007 \\
(1)<(3)\end{array}$ \\
\hline Gender (women \%) & 77 (50.1\%) & $18(39.1 \%)$ & $13(52.0 \%)$ & $8(53.3 \%)$ & $38(58.5 \%)$ & 0.253 \\
\hline Quality of life score & $79.87 \pm 16.29$ & $95.2 \pm 12.3$ & $85.7 \pm 9.9$ & $79.3 \pm 9.8$ & $66.9 \pm 10.2$ & $\begin{array}{l}0.000 \\
(1)>(2)=(3)>(4)\end{array}$ \\
\hline$\%$ QOL score $\leq 65$ & $30(19.9 \%)$ & $1(2.2 \%)$ & $0(0.0 \%)$ & $1(6.7 \%)$ & $28(43.1 \%)$ & 0.000 \\
\hline Marital Status & & & & & & 0.519 \\
\hline Married & $118(78.1 \%)$ & $35(76.1 \%)$ & $19(76.0 \%)$ & $14(93.3 \%)$ & $50(76.9 \%)$ & \\
\hline Others & $33(21.9 \%)$ & $11(23.9 \%)$ & $6(24.0 \%)$ & $1(6.7 \%)$ & $15(23.1 \%)$ & \\
\hline Primary education & & & & & $x^{2}=6.683$ & 0.083 \\
\hline$\leq 6$ years & $85(56.3 \%)$ & $19(41.3 \%)$ & $14(56.0 \%)$ & $10(66.7 \%)$ & $42(64.6 \%)$ & \\
\hline$>6$ years & $66(43.7 \%)$ & $27(58.7 \%)$ & $11(44.0 \%)$ & $5(33.3 \%)$ & $23(35.4 \%)$ & \\
\hline Employment Status & & & & & & 0.059 \\
\hline Unemployed & $132(87.4 \%)$ & $38(82.6 \%)$ & $19(76.0 \%)$ & $15(100.0 \%)$ & $60(92.3 \%)$ & \\
\hline Employed & $19(12.6 \%)$ & $8(17.4 \%)$ & $6(24.0 \%)$ & $0(0.0 \%)$ & $5(7.7 \%)$ & \\
\hline Religion & & & & & & 0.564 \\
\hline nil & $49(32.5 \%)$ & $14(30.4 \%)$ & $8(32.0 \%)$ & $4(26.7 \%)$ & $23(35.4 \%)$ & \\
\hline Buddhism & $65(43.0 \%)$ & $23(50.0 \%)$ & $10(40.0 \%)$ & $6(40.0 \%)$ & $26(40.0 \%)$ & \\
\hline Christianity & $3(2.0 \%)$ & $0(0.0 \%)$ & $1(4.0 \%)$ & $1(6.7 \%)$ & $1(1.5 \%)$ & \\
\hline Catholicism & $12(7.9 \%)$ & $1(2.2 \%)$ & $1(4.0 \%)$ & $3(20.0 \%)$ & $79(10.8 \%)$ & \\
\hline Taoism & $21(13.9 \%)$ & $8(17.4 \%)$ & $5(20.0 \%)$ & $1(6.7 \%)$ & $7(10.8 \%)$ & \\
\hline miscellaneous & $1(0.7 \%)$ & $0(0.0 \%)$ & $0(0.0 \%)$ & $0(0.0 \%)$ & $1(1.5 \%)$ & \\
\hline Monthly income (USD) & & & & & & 0.494 \\
\hline$<300$ & $87(57.6 \%)$ & $24(52.2 \%)$ & $12(48.0 \%)$ & $10(66.7 \%)$ & $41(63.1 \%)$ & \\
\hline $300-1000$ & $37(24.5 \%)$ & $9(19.6 \%)$ & $7(28.0 \%)$ & $4(26.7 \%)$ & $17(26.2 \%)$ & \\
\hline $1000-2000$ & $17(11.3 \%)$ & $8(17.4 \%)$ & $4(16.0 \%)$ & $1(6.7 \%)$ & $4(6.2 \%)$ & \\
\hline$>2000$ & $10(6.6 \%)$ & $5(10.9 \%)$ & $2(8.0 \%)$ & $0(0.0 \%)$ & $3(4.6 \%)$ & \\
\hline Living & & & & & & 0.335 \\
\hline alone & $5(3.3 \%)$ & $2(4.3 \%)$ & $0(0.0 \%)$ & $1(6.7 \%)$ & $2(3.1 \%)$ & \\
\hline with family & $139(92.1 \%)$ & $44(95.7 \%)$ & $22(88.0 \%)$ & $13(86.7 \%)$ & $60(92.3 \%)$ & \\
\hline other & $7(4.6 \%)$ & $0(0.0 \%)$ & $3(12.0 \%)$ & $1(6.7 \%)$ & $3(4.6 \%)$ & \\
\hline Diabetes mellitus & $84(55.6 \%)$ & $27(58.7 \%)$ & $14(56.0 \%)$ & $8(53.3 \%)$ & $35(53.8 \%)$ & 0.961 \\
\hline BUN (mg/dL) & $75.2 \pm 20.9$ & $79.7 \pm 19.2$ & $78.8 \pm 21.8$ & $75.1 \pm 22.6$ & $70.8 \pm 21.1$ & 0.129 \\
\hline Creatinine (mg/dL) & $10.34 \pm 2.58$ & $11.3 \pm 2.5$ & $10.7 \pm 2.7$ & $9.9 \pm 2.0$ & $9.7 \pm 2.5$ & $\begin{array}{l}0.008 \\
(1)>(4)\end{array}$ \\
\hline Sodium $(\mathrm{mmol} / \mathrm{L})$ & $136.9 \pm 4.1$ & $137.3 \pm 2.6$ & $137.0 \pm 4.2$ & $137.0 \pm 4.6$ & $136.5 \pm 4.8$ & 0.806 \\
\hline Potassium $(\mathrm{mmol} / \mathrm{L})$ & $4.44 \pm 0.97$ & $4.5 \pm 0.8$ & $4.6 \pm 0.8$ & $4.5 \pm 1.0$ & $4.3 \pm 1.1$ & 0.660 \\
\hline Calcium (mg/dL) & $9.30 \pm 0.87$ & $9.3 \pm 0.9$ & $9.3 \pm 0.7$ & $9.0 \pm 1.1$ & $9.4 \pm 0.9$ & 0.610 \\
\hline Phosphate (mg/dL) & $4.90 \pm 1.47$ & $4.9 \pm 1.4$ & $5.5 \pm 1.5$ & $5.5 \pm 1.4$ & $4.5 \pm 1.4$ & 0.015 \\
\hline Cax P product & $45.70 \pm 14.65$ & $46.1 \pm 13.9$ & $50.8 \pm 16.3$ & $49.1 \pm 11.8$ & $42.7 \pm 14.7$ & 0.081 \\
\hline Albumin (g/dL) & $3.65 \pm 0.37$ & $3.8 \pm 0.3$ & $3.7 \pm 0.4$ & $3.6 \pm 0.3$ & $3.5 \pm 0.4$ & $\begin{array}{l}0.001 \\
(1)>(4)\end{array}$ \\
\hline Glucose (mg/dL) & $153.2 \pm 65.8$ & $153.3 \pm 57.6$ & $147.4 \pm 69.9$ & $157.1 \pm 49.8$ & $154.5 \pm 73.5$ & 0.966 \\
\hline GOT (IU/L) & $18.4 \pm 10.1$ & $18.3 \pm 9.4$ & $18.0 \pm 6.0$ & $20.9 \pm 20.3$ & $18.2 \pm 8.5$ & 0.802 \\
\hline GPT (IU/L) & $19.1 \pm 20.0$ & $18.2 \pm 15.5$ & $18.2 \pm 10.8$ & $25.1 \pm 47.3$ & $18.8 \pm 15.1$ & 0.689 \\
\hline $\mathrm{Kt} / \mathrm{V}$ of urea & $1.34 \pm 0.22$ & $1.4 \pm 0.3$ & $1.4 \pm 0.2$ & $1.3 \pm 0.1$ & $1.3 \pm 0.2$ & 0.160 \\
\hline Dialysis vintage (years) & $4.5 \pm 3.9$ & $3.9 \pm 3.8$ & $4.8 \pm 3.2$ & $5.6 \pm 4.4$ & $4.7 \pm 4.1$ & 0.437 \\
\hline $\operatorname{ALKP}(\mathrm{U} / \mathrm{L})$ & $307.6 \pm 138.6$ & $297.9 \pm 160.8$ & $315.5 \pm 137.7$ & $333.1 \pm 116.7$ & $305.6 \pm 128.4$ & 0.846 \\
\hline Triglyceride $(\mathrm{mg} / \mathrm{dL})$ & $169.8 \pm 111.9$ & $164.8 \pm 81.5$ & $158.7 \pm 128.5$ & $175.1 \pm 94.7$ & $176.3 \pm 128.1$ & 0.901 \\
\hline Cholesterol (mg/dL) & $159.8 \pm 34.9$ & $166.6 \pm 39.4$ & $153.3 \pm 35.1$ & $150.7 \pm 24.2$ & $159.6 \pm 33.2$ & 0.306 \\
\hline Ferritin $(\mathrm{ng} / \mathrm{mL})$ & $460.8 \pm 444.5$ & $410.9 \pm 215.1$ & $644.4 \pm 920.4$ & $391.8 \pm 437.9$ & $441.4 \pm 233.5$ & 0.149 \\
\hline i-parathyroid hormone $(\mathrm{pg} / \mathrm{mL})$ & $338.0 \pm 271.4$ & $338.9 \pm 272.2$ & $453.7 \pm 346.5$ & $278.3 \pm 201.7$ & $306.7 \pm 244.0$ & 0.104 \\
\hline Hemoglobin $(\mathrm{g} / \mathrm{dL})$ & $10.78 \pm 1.51$ & $10.9 \pm 1.5$ & $10.6 \pm 1.4$ & $10.8 \pm 1.8$ & $10.8 \pm 1.5$ & 0.950 \\
\hline Platelet $(\mathrm{k} / \mu \mathrm{L})$ & $177.1 \pm 64.9$ & $170.7 \pm 45.9$ & $169.5 \pm 64.9$ & $208.4 \pm 80.1$ & $177.3 \pm 71.6$ & 0.234 \\
\hline
\end{tabular}

Table 2. Demographic characteristics based on the Taiwanese Depression Questionnaire (TDQ) score $(\mathrm{n}=151)$. Data are presented as the mean \pm standard deviation, or as the count number (percentage) in each TDQ subgroup. The $p$ values are from Chi square test, Fisher's exact test, or ANOVA among the 4 subgroups with post hoc comparisons performed using the Scheffe test (shown if significant, $p<0.05$ ). Between-group comparisons of the 3 -year mortality are performed by $z$-tests, and those with $\mathrm{p}<0.05$ are shown. The abbreviations are listed in Table 1. 


\begin{tabular}{|c|c|c|c|c|c|c|c|c|c|c|c|}
\hline & & \multicolumn{3}{|c|}{$\begin{array}{l}\text { Logistic regression, Non- } \\
\text { adjusted }\end{array}$} & \multicolumn{3}{|c|}{$\begin{array}{l}\text { Logistic regression, adjusted } \\
\text { by age, albumin }\end{array}$} & \multicolumn{3}{|c|}{$\begin{array}{l}\text { Cox regression, adjusted by } \\
\text { age, albumin }\end{array}$} & \multirow{3}{*}{\begin{tabular}{|l|} 
Log rank test in Kaplan- \\
Meier analysis
\end{tabular}} \\
\hline & & \multirow{2}{*}{\begin{tabular}{|l|}
$\operatorname{Exp}(B)$ \\
1.458 \\
\end{tabular}} & \multicolumn{2}{|c|}{ 95\% C.I } & \multirow{2}{*}{\begin{tabular}{|l|}
$\operatorname{Exp}(\mathbf{B})$ \\
1.323 \\
\end{tabular}} & \multicolumn{2}{|c|}{ 95\% C.I } & \multirow{2}{*}{\begin{tabular}{|l|} 
HR \\
1.259
\end{tabular}} & \multicolumn{2}{|c|}{ 95\% C.I } & \\
\hline \multirow{7}{*}{ Somatic symptoms } & 4 & & 1.077 & 1.975 & & 0.957 & 1.830 & & 0.965 & 1.641 & \\
\hline & 5 & 1.161 & 0.819 & 1.644 & 1.011 & 0.693 & 1.473 & 1.029 & 0.764 & 1.386 & 0.776 \\
\hline & 6 & 1.275 & 0.878 & 1.852 & 1.183 & 0.792 & 1.766 & 1.167 & 0.852 & 1.599 & 0.438 \\
\hline & 8 & 1.231 & 0.883 & 1.718 & 1.014 & 0.699 & 1.471 & 1.037 & 0.772 & 1.392 & 0.473 \\
\hline & 10 & 1.145 & 0.839 & 1.561 & 1.000 & 0.716 & 1.397 & 1.049 & 0.808 & 1.361 & 0.197 \\
\hline & 11 & 1.423 & 1.023 & 1.980 & 1.299 & 0.918 & 1.839 & 1.284 & 0.993 & 1.661 & 0.135 \\
\hline & 17 & 1.597 & 1.143 & 2.232 & 1.443 & 1.010 & 2.061 & 1.351 & 1.022 & 1.785 & 0.036 \\
\hline \multirow{11}{*}{$\begin{array}{l}\text { Affective and } \\
\text { cognitive symptoms }\end{array}$} & 1 & 1.315 & 0.943 & 1.834 & 1.231 & 0.865 & 1.752 & 1.147 & 0.876 & 1.503 & 0.111 \\
\hline & 2 & 1.640 & 1.204 & 2.233 & 1.535 & 1.101 & 2.140 & 1.373 & 1.074 & 1.754 & 0.002 \\
\hline & 3 & 1.420 & 1.046 & 1.929 & 1.314 & 0.951 & 1.815 & 1.232 & 0.958 & 1.583 & 0.088 \\
\hline & 7 & 1.632 & 1.157 & 2.301 & 1.489 & 1.029 & 2.156 & 1.380 & 1.031 & 1.849 & 0.001 \\
\hline & 9 & 1.421 & 1.026 & 1.968 & \begin{tabular}{|l|l}
1.347 \\
\end{tabular} & 0.954 & 1.901 & 1.273 & 0.979 & 1.657 & 0.083 \\
\hline & 12 & \begin{tabular}{|l|l|}
1.549 \\
\end{tabular} & 1.114 & 2.156 & \begin{tabular}{|l|l|}
1.417 \\
\end{tabular} & 1.001 & 2.006 & 1.318 & \begin{tabular}{|l|l}
1.009 \\
\end{tabular} & 1.723 & 0.012 \\
\hline & 13 & 1.638 & 1.187 & 2.262 & 1.519 & 1.078 & 2.140 & 1.333 & 1.030 & 1.725 & \begin{tabular}{|l|l|}
0.003 \\
\end{tabular} \\
\hline & 14 & 1.513 & 1.080 & 2.120 & \begin{tabular}{|l|}
1.509 \\
\end{tabular} & 1.045 & 2.178 & 1.365 & 1.039 & 1.794 & 0.063 \\
\hline & 15 & \begin{tabular}{|l|l|} 
\\
\end{tabular} & 1.033 & 1.977 & 1.353 & 0.949 & 1.928 & 1.239 & 0.946 & 1.625 & \begin{tabular}{|l|l|} 
\\
\end{tabular} \\
\hline & 16 & 1.421 & 1.024 & 1.973 & 1.357 & 0.954 & 1.931 & 1.242 & 0.954 & 1.616 & \begin{tabular}{|l|l|} 
\\
\end{tabular} \\
\hline & 18 & \begin{tabular}{|l|l|} 
\\
\end{tabular} & \begin{tabular}{|l|l|}
1.091 \\
\end{tabular} & 1.995 & \begin{tabular}{|l|l}
1.358 \\
\end{tabular} & 0.986 & \begin{tabular}{|l}
1.870 \\
\end{tabular} & $\begin{array}{ll}1.242 \\
\end{array}$ & \begin{tabular}{|l|}
0.972 \\
\end{tabular} & 1.586 & 0.016 \\
\hline
\end{tabular}

Table 3. Statistical analyses of the association between patient mortality and individual items in the Taiwanese Depression Questionnaire. The odds ratios are calculated by the beta exponential $[\operatorname{Exp}(\mathrm{B})]$. P values for the logrank test of Kaplan-Meier survival analysis are presented. The question order is rearranged into the somatic and affective/cognitive subgroups. C.I. indicates the confidence interval.

depression and mortality have examined the outcomes between depressed and non-depressed subjects. In contrast, we divided our subjects into 4 groups based on their depression scores: normal (0-8), low abnormal (9-14), high abnormal (15-18), and depressive (19-54). Individuals with high abnormal scores showed a mortality rate that was as high as the rate for those regarded as depressive. This finding implies the importance of early intervention in those with high abnormal scores.

Only two previous studies have demonstrated an association between the cognitive symptoms in depression and mortality in hemodialysis patients. Kimmel et al. ${ }^{25}$ found that the relative risk of death in chronic hemodialysis patients was 1.32 (95\% confidence interval 1.13 to 1.55 ) based on the Beck Depression Inventory scores and 1.23 (95\% confidence interval 1.05 to 1.43 ) based on the Cognitive Depression Index. Another study by Peterson et al. ${ }^{26}$ found that the CDI scores at one-year follow-up were already different between the surviving and non-surviving patients on hemodialysis or peritoneal dialysis, although their BDI scores did not differ. These two studies highlight the importance of cognitive symptoms in association with mortality in dialysis patients; however, their results should not be interpreted as indicating that the somatic symptoms are less significant.

The reason why the somatic indicators fail to predict mortality in hemodialysis patients is unknown. One possibility is that hemodialysis treats uremia-related somatic symptoms, such as fatigue, poor appetite and concentration difficulty, and might therefore minimize the impact of somatic symptoms in patients on hemodialysis. Our analysis of the association factors supports this notion. The somatic subscale score is not correlated with two surrogate uremic markers, blood urea nitrogen and creatinine. Consequently, the somatic symptoms may become indistinguishable between the survivors and non-survivors. In contrast, in patients with myocardial infarction or chronic heart failure ${ }^{24,29}$, somatic/affective symptoms rather than cognitive/affective symptoms are associated with mortality and cardiovascular outcomes. Somatic symptoms such as fatigue and appetite may directly reflect the physical condition as well as the disease severity of these patients, and therefore, the somatic symptoms are associated with mortality.

Another hypothesis is that perception of illness may be correlated with mortality, a dimension which is potentially captured through affective/cognitive symptoms rather than somatic symptoms. In other words, patients with more severe disease may also have more prominent cognitive symptoms, and therefore, cognitive symptoms are presumably more associated with mortality. Sacks ${ }^{30}$ reported that the correlation coefficient between the Cognitive Depression Index and the perception of illness score was $0.49(\mathrm{p}<0.001)$ in dialysis patients, whereas the correlation coefficient was $0.67(\mathrm{p}<0.001)$ between the BDI and the perception of illness score. However, no data were presented regarding the association between the somatic symptoms and the perception of illness.

Another possible argument is that self-report scales have lower specificity for detecting only patients with clear depressive disorders, and therefore, the study sample might overestimate the prevalence of depressive symptoms by including patients with only somatic symptoms related to their hemodialysis. That is, the somatic symptoms of depression may be found in so many patients and with such a high degree of severity that these symptoms cannot differentiate between survivors and non-survivors. However, our analysis of the frequency distribution of the responses to each question counters this argument (Fig. 3). In fact, for most questions, far more participants 

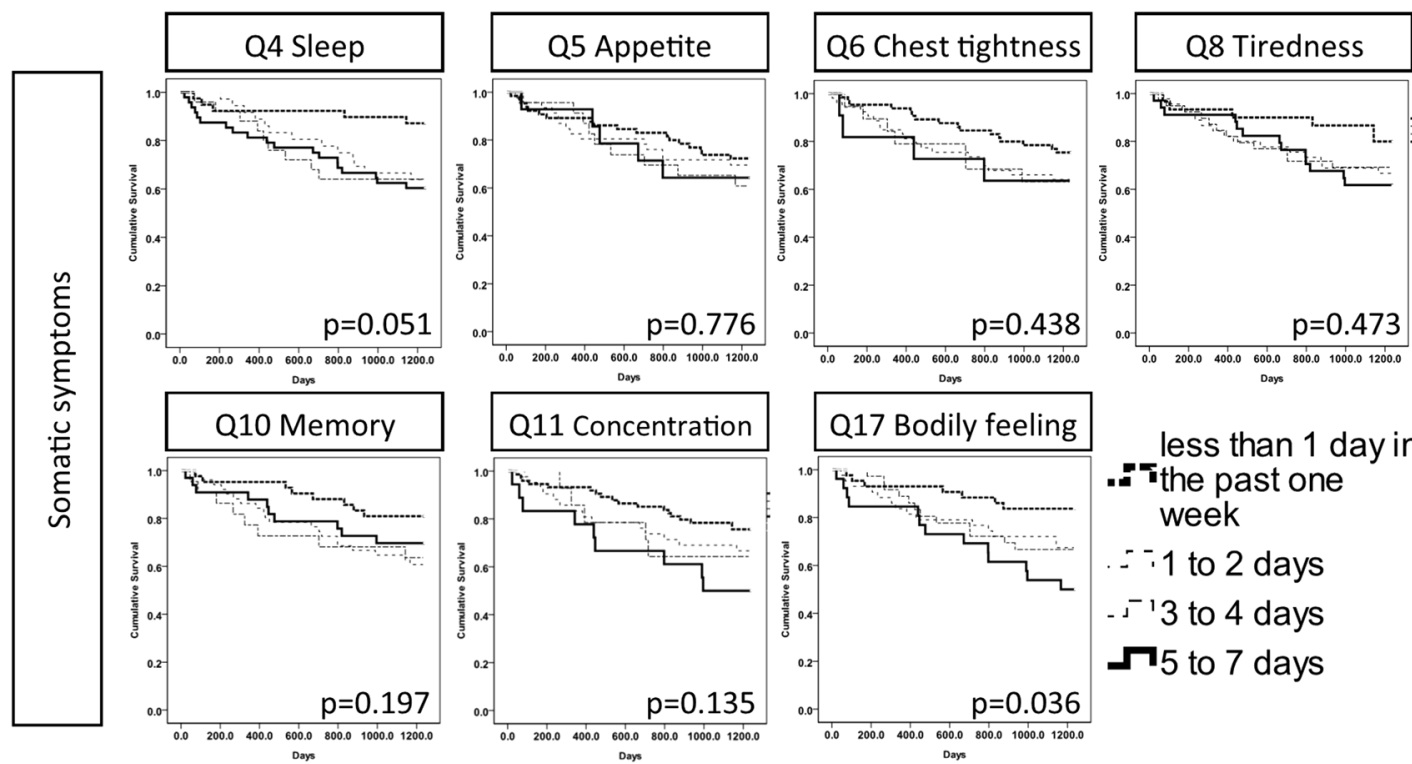

less than 1 day in

.Tthe past one week

$=-1$ to 2 days

- s 3 to 4 days

$\boldsymbol{5}$ to 7 days
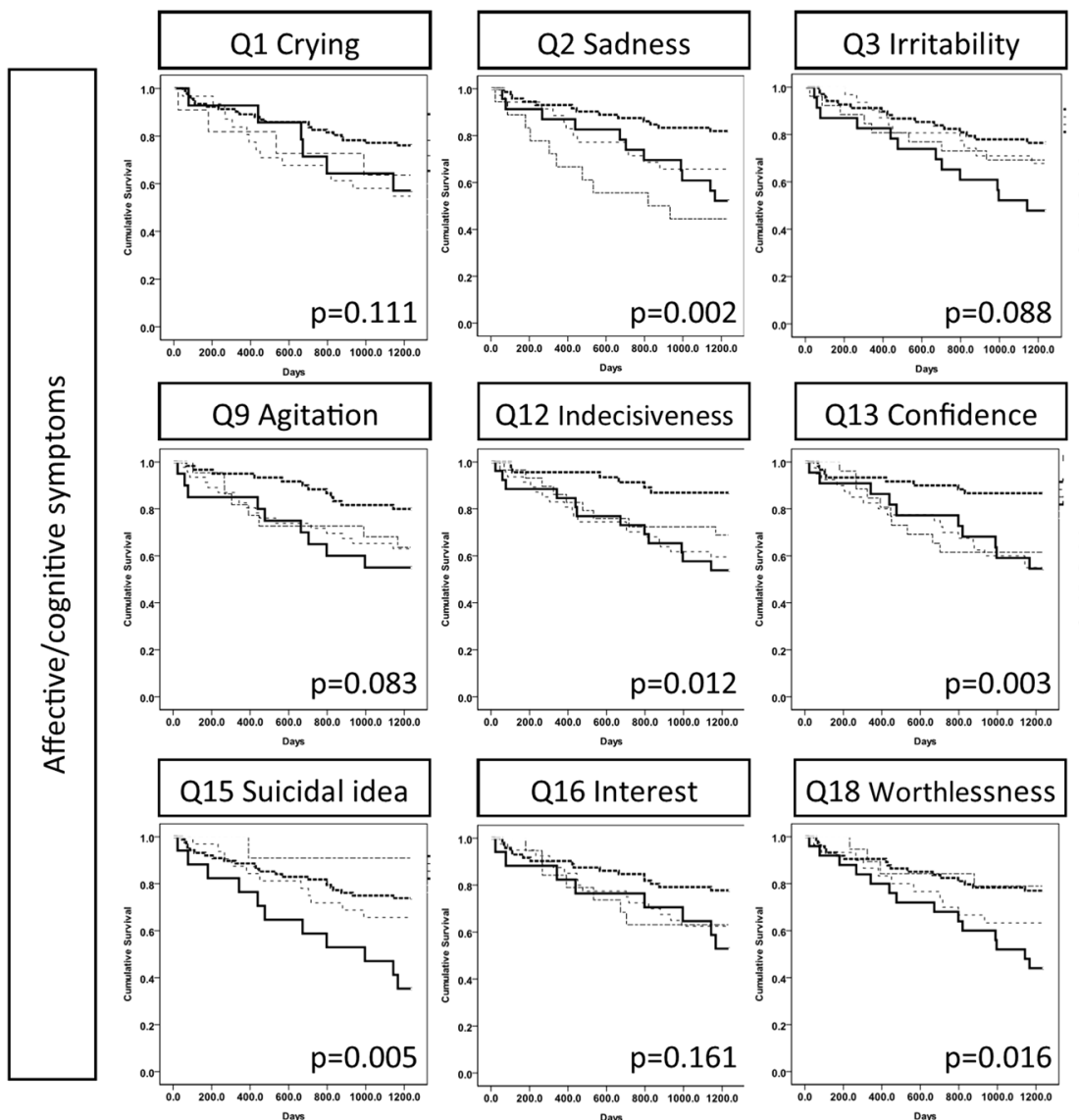

Q7 Uneasiness

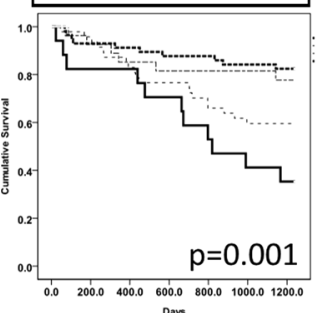

Q12 Indecisiveness
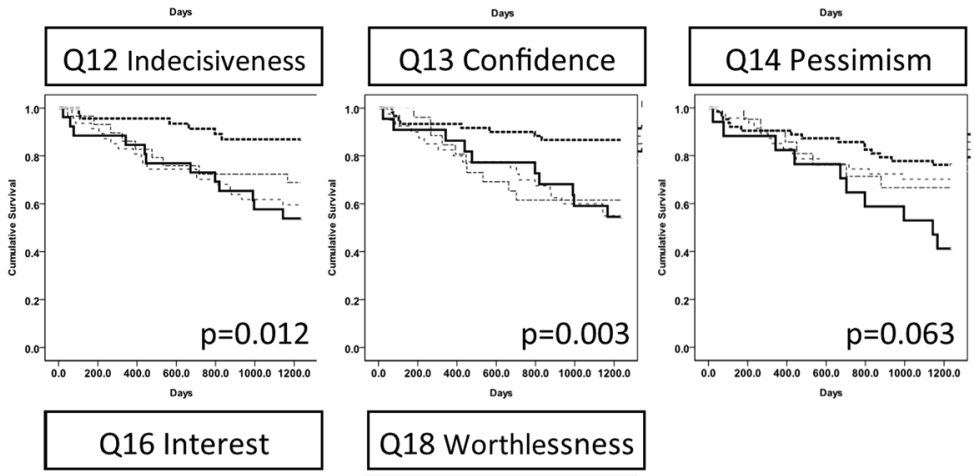

Q16 Interest
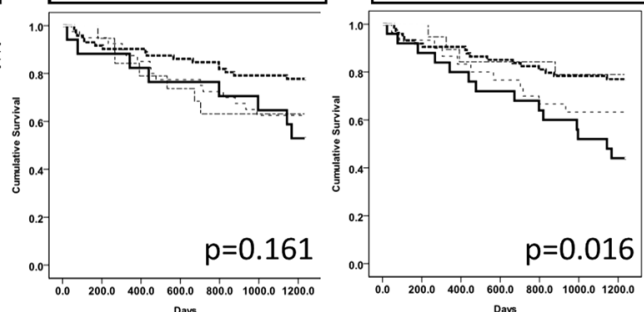

Figure 1. Kaplan-Meier survival curves by individual depressive symptoms. The subjects are divided into 4 groups according to the frequency of the symptoms (the answers to each question). The individual p values of the log-rank test are shown.

did not report symptoms than reported having symptoms. The frequency distribution patterns for each question were also not significantly related to the associations of the questions with mortality.

We used 4 different analytic tools to identify the questions that might predict mortality (Table 3, Figs 1 and 2). The tools differ mathematically; therefore, the questions that pass all tests should have high predictive power. Interestingly, the logistic regression analyses and Cox regression models identified exactly the same 5 affective and cognitive questions that were associated with mortality. The Kaplan-Meier analysis illustrated the survival difference from the responses to each question, and the questions that displayed statistical significance were very 


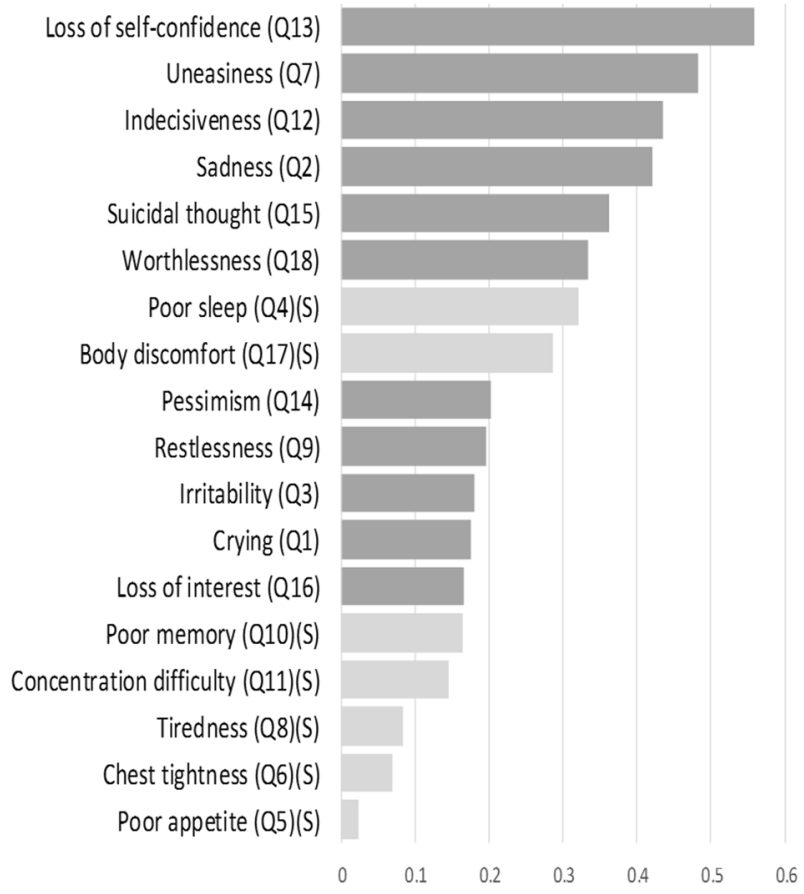

Figure 2. Information value plot of each question in the Taiwanese Depression Questionnaire in predicting mortality. Questions regarding somatic symptoms are indicated by $S$ in parentheses $(S)$ and lighter shades in the bars.

\begin{tabular}{|l|l|l|l|}
\hline Item number & $\begin{array}{l}\text { Affective/cognitive or } \\
\text { Somatic }(\mathbf{U}=\mathbf{1 0}, \mathbf{p}<\mathbf{0 . 0 5})\end{array}$ & Item description & $\begin{array}{l}\text { Spearman correlation } \\
\text { coefficient (rho) }\end{array}$ \\
\hline 13 & A & Loss of self-confidence & -0.703 \\
\hline 2 & A & Sadness & -0.669 \\
\hline 18 & A & Worthlessness & -0.668 \\
\hline 7 & A & Uneasiness & -0.643 \\
\hline 3 & A & Irritability & -0.638 \\
\hline 16 & A & Loss of interest & -0.629 \\
\hline 15 & A & Suicidal thought & -0.609 \\
\hline 12 & A & Indecisiveness & -0.608 \\
\hline 17 & S & Bodily discomfort & -0.605 \\
\hline 8 & S & Tiredness & -0.581 \\
\hline 9 & A & Restlessness & -0.578 \\
\hline 4 & S & Poor sleep & -0.550 \\
\hline 1 & A & Crying & -0.549 \\
\hline 6 & S & Chest tightness & -0.540 \\
\hline 10 & S & Poor memory & -0.527 \\
\hline 14 & A & Pessimism & -0.522 \\
\hline 11 & S & Concentration difficulty & -0.504 \\
\hline 5 & S & Poor appetite & -0.417 \\
\hline
\end{tabular}

Table 4. Spearman's rank order correlation coefficient (rho) between each question in the Taiwanese Depression Questionnaire and the total score of the WHO Quality of Life Questionnaire-brief version. All $p$ values are less than 0.001 . The items are listed in order from the highest negative correlation. The MannWhitney $\mathrm{U}$ test is used to compare the order between the affective/cognitive items and the somatic items.

similar to those found by the aforementioned 2 methods. There were 4 affective and cognitive questions showing statistical significance in all three methods, and they were the same ones that topped the information value plot. Therefore, we are confident in reporting the importance of four key affective and cognitive symptoms, which are sad mood (Q2), tenseness (Q7), indecisiveness (Q12), and low self-confidence (Q13), to predict mortality. 


\begin{tabular}{|c|c|c|c|c|}
\hline & \begin{tabular}{|l|} 
Somatic \\
subscale
\end{tabular} & $\begin{array}{l}p \text { value of } t \text {-test, or ANOVA } \\
\text { and post hoc Scheffe test }\end{array}$ & $\begin{array}{l}\text { Affective/Cognitive } \\
\text { subscale }\end{array}$ & $\begin{array}{l}p \text { value of } t \text {-test, or ANOVA } \\
\text { and post hoc Scheffe test }\end{array}$ \\
\hline Gender & & 0.011 & & 0.051 \\
\hline Men (74) & $7.15 \pm 5.20$ & & $9.01 \pm 8.52$ & \\
\hline Women (77) & $9.42 \pm 5.67$ & & $12.04 \pm 10.34$ & \\
\hline Marital status & & 0.685 & & 0.210 \\
\hline Married (118) & $8.19 \pm 5.28$ & & $9.97 \pm 9.04$ & \\
\hline Other (33) & $8.70 \pm 6.48$ & & $12.67 \pm 11.2$ & \\
\hline Education & & 0.021 & & 0.044 \\
\hline$\leq 6$ years $(85)$ & $9.24 \pm 5.18$ & & $11.92 \pm 9.9$ & \\
\hline$>6$ years $(66)$ & $7.11 \pm 5.80$ & & $8.8 \pm 8.93$ & \\
\hline Occupation & & 0.352 & & 0.269 \\
\hline Unemployed (132) & $8.48 \pm 5.44$ & & $10.92 \pm 9.45$ & \\
\hline Employed (19) & $7.05 \pm 6.23$ & & $8.05 \pm 10.41$ & \\
\hline Religion & & $\mathrm{F}=0.284, \mathrm{p}=0.921$ & & $\mathrm{~F}=0.618, \mathrm{p}=0.686$ \\
\hline $\operatorname{nil}(49)$ & $8.53 \pm 5.15$ & & $11.16 \pm 9.62$ & \\
\hline Buddhism (65) & $7.85 \pm 6.08$ & & $10.28 \pm 9.67$ & \\
\hline Christianity (3) & $9.67 \pm 3.06$ & & $9.33 \pm 8.08$ & \\
\hline Catholicism (12) & $9.67 \pm 4.23$ & & $14 \pm 10.05$ & \\
\hline Taoism (21) & $8.19 \pm 5.99$ & & $8.19 \pm 9.52$ & \\
\hline Miscellaneous (1) & 9.00 & & 11 & \\
\hline Monthly income (USD) & & $\mathrm{F}=3.491, \mathbf{p}=\mathbf{0 . 0 1 9}$ & & $\mathrm{F}=1.657, \mathrm{p}=0.179$ \\
\hline$<300(17)$ & $8.43 \pm 5.16$ & $(2)>(3)$ & $10.8 \pm 9.29$ & \\
\hline $300-1000(10)$ & $10.00 \pm 6.33$ & & $12.43 \pm 10.84$ & \\
\hline $1000-2000(87)$ & $5.47 \pm 5.19$ & & $6.76 \pm 7.77$ & \\
\hline$>2000(37)$ & $5.80 \pm 4.05$ & & $7.9 \pm 8.88$ & \\
\hline Living & & $\mathrm{F}=0.043, \mathrm{p}=0.958$ & & $\mathrm{~F}=0.749, \mathrm{p}=0.475$ \\
\hline Alone (5) & $9.00 \pm 5.79$ & & $11.00 \pm 10.15$ & \\
\hline with family (139) & $8.27 \pm 5.62$ & & $10.32 \pm 9.51$ & \\
\hline Other (7) & $8.43 \pm 4.35$ & & $14.86 \pm 11.16$ & \\
\hline Diabetes mellitus & & 0.314 & & 0.286 \\
\hline No (67) & $8.82 \pm 5.85$ & & $11.51 \pm 10.41$ & \\
\hline Yes (84) & $7.89 \pm 5.29$ & & $9.8 \pm 8.86$ & \\
\hline
\end{tabular}

Table 5. Scores of the somatic subscale and the affective/cognitive subscale of the Taiwanese Depression Questionnaire based on demographic characteristics. Data are presented as the mean \pm standard deviation. USD: US dollars.

Our results are the first to demonstrate that quality of life is more correlated with affective and cognitive symptoms than with somatic symptoms. The top three items that showed high correlation coefficients were loss of self-confidence, sadness, and worthlessness, all of which were negative thoughts in terms of depression symptomatology. Somatic symptoms displayed lower correlations. This result emphasizes how easily quality of life can be influenced by a melancholic mood. Another interesting point was that the question regarding body pain was the only somatic symptom that was associated with mortality, and was also the most influential question relating somatic symptoms to quality of life.

Despite the challenges in correctly diagnosing depression in end-stage renal disease patients due to overlapping symptomatology, our findings appear to support the existence of depression as a distinct and clinically significant entity in this population. The finding that the somatic scores are associated with many extrinsic factors implies that the somatic symptoms of depression may be secondary in hemodialysis patients. However, the data showing lack of associations of the affective and cognitive scores with various factors are compatible with the fact that depression is currently regarded as more of a neurobiological disease rather than an illness only caused by psychological or environmental stresses ${ }^{31}$. Therefore, depression in hemodialysis patients should not be overshadowed by their somatic complaints.

This study has several limitations. First, the symptoms of depression were defined using a self-reported questionnaire instead of diagnosis by a psychiatrist. We tried to minimize individual differences in interpreting the questions by acquiring the answers through interviews performed by registered nurses, instead of simply giving the questionnaire to our subjects. The second concern is the low sample number. Although a larger sample size might have demonstrated significant associations with somatic symptoms of depression, this association would be likely less significant than that of affective and cognitive symptoms with mortality. Nevertheless, a larger sample size might allow more in-depth subgroup analyses. For example, we need to recruit more subjects to determine whether the somatic symptoms are associated with mortality in individuals with a shorter dialysis vintage. Third, the Likert scale, which ranges from 0 to 3, is based on the frequency of a certain symptom over the past week, and 


\begin{tabular}{|l|l|l|l|l|}
\hline & $\begin{array}{l}\text { Pearson correlation coefficient with } \\
\text { Somatic subscale }\end{array}$ & $\boldsymbol{p}$ value & $\begin{array}{l}\text { Pearson correlation coefficient } \\
\text { with Affective/Cognitive subscale }\end{array}$ & $\boldsymbol{p}$ value \\
\hline Age & 0.193 & $\mathbf{0 . 0 1 8}$ & 0.095 & 0.248 \\
\hline BUN & -0.155 & $\mathbf{0 . 0 5 7}$ & -0.221 & $\mathbf{0 . 0 0 6}$ \\
\hline Creatinine & -0.347 & $\mathbf{0 . 0 0 0}$ & -0.308 & $\mathbf{0 . 0 0 0}$ \\
\hline Sodium & -0.076 & 0.354 & -0.080 & 0.330 \\
\hline Potassium & -0.117 & 0.152 & -0.142 & $\mathbf{0 . 0 8 3}$ \\
\hline Calcium & 0.040 & 0.629 & 0.049 & 0.552 \\
\hline Phosphate & -0.106 & 0.195 & -0.179 & $\mathbf{0 . 0 2 8}$ \\
\hline Cax P product & -0.080 & 0.327 & -0.142 & $\mathbf{0 . 0 8 2}$ \\
\hline Albumin & -0.317 & $\mathbf{0 . 0 0 0}$ & -0.298 & $\mathbf{0 . 0 0 0}$ \\
\hline Glucose & 0.002 & 0.981 & 0.004 & 0.960 \\
\hline GOT & 0.111 & 0.176 & 0.020 & 0.810 \\
\hline GPT & 0.107 & 0.190 & 0.023 & 0.783 \\
\hline Kt/V of urea & -0.102 & 0.213 & -0.108 & 0.187 \\
\hline Dialysis vintage (years) & 0.154 & $\mathbf{0 . 0 5 8}$ & 0.136 & $\mathbf{0 . 0 9 7}$ \\
\hline ALKP & 0.113 & 0.169 & 0.034 & 0.676 \\
\hline Triglyceride & -0.002 & 0.984 & 0.008 & 0.922 \\
\hline Cholesterol & -0.111 & 0.176 & -0.083 & 0.312 \\
\hline Ferritin & 0.040 & 0.627 & -0.065 & 0.429 \\
\hline i-parathyroid hormone & 0.034 & 0.676 & -0.077 & 0.347 \\
\hline Hemoglobin & -0.029 & 0.725 & 0.051 & 0.531 \\
\hline Platelet & 0.023 & 0.783 & 0.057 & 0.486 \\
\hline
\end{tabular}

Table 6. Pearson's correlation coefficient and $\mathrm{p}$ values of the biochemical data with the somatic subscale and the affective/cognitive subscale. $\mathrm{p}$ values lower than 0.1 are labeled in bold. ALKP: alkaline phosphatase, BUN: blood urea nitrogen, Ca x P: calcium and phosphate product, GOT: glutamic oxaloacetic transaminase, GPT: glutamic pyruvic transaminase, i-parathyroid hormone: intact parathyroid hormone, Kt/V: dialysis adequacy by dialyzer clearance of urea $(\mathrm{K})$ times time $(\mathrm{t})$ divided by volume $(\mathrm{V})$ of the urea distribution.

\begin{tabular}{|c|c|c|c|c|c|c|c|c|}
\hline \multirow[b]{3}{*}{ Creatinine } & \multicolumn{4}{|c|}{ Multiple linear regression model with Somatic subscale } & \multicolumn{4}{|c|}{$\begin{array}{l}\text { Multiple linear regression model with Affective/ } \\
\text { cognitive subscale }\end{array}$} \\
\hline & \multirow{2}{*}{\begin{tabular}{|l|} 
Standardized beta \\
-0.229
\end{tabular}} & \multicolumn{2}{|c|}{$\begin{array}{l}\text { 95\% confidence } \\
\text { interval }\end{array}$} & \multirow{2}{*}{\begin{tabular}{|l|}
$p$ value \\
0.009
\end{tabular}} & \multirow{2}{*}{\begin{tabular}{|l|} 
Standardized beta \\
-0.175
\end{tabular}} & \multicolumn{2}{|c|}{$\begin{array}{l}\text { 95\% confidence } \\
\text { interval }\end{array}$} & \multirow{2}{*}{\begin{tabular}{|l|}
$p$ value \\
0.056
\end{tabular}} \\
\hline & & -0.860 & -0.123 & & & -1.315 & 0.017 & \\
\hline Albumin & -0.203 & -5.608 & -0.493 & 0.020 & -0.205 & -9.780 & -0.897 & 0.019 \\
\hline Dialysis vintage & 0.157 & 0.011 & 0.435 & 0.039 & 0.137 & -0.039 & 0.711 & 0.079 \\
\hline Age & 0.058 & -0.040 & 0.087 & 0.469 & ni & $\mathrm{ni}$ & ni & ni \\
\hline Potassium & ni & ni & ni & ni & -0.060 & -2.157 & 0.964 & 0.451 \\
\hline Phosphate & ni & ni & ni & $\mathrm{ni}$ & -0.068 & -1.523 & 0.641 & \begin{tabular}{|l|}
0.422 \\
\end{tabular} \\
\hline
\end{tabular}

Table 7. Multiple linear regression model of select variables with the somatic or affective/cognitive subscales. ni: not included.

therefore, the severity is not measured by degree. A symptom that is severe but manifests only once a week is by definition scored only one point, which makes these symptoms less useful in predicting the outcomes. Fourth, the study did not adjust for anxiety. It is known that anxiety is associated with an increased mortality rate in patients undergoing hemodialysis ${ }^{32}$. DSM-5 (the Diagnostic and Statistical Manual of Mental Disorders, 5th Edition) criteria for generalized anxiety disorder include "increased muscle aches or soreness," which are overlapped with the physical complaints represented by questions 6 (chest tightness) and 17 (headache, dizziness, palpitation and abdominal distress) in the somatic subscale of the TDQ. The association we found in this study between question 17 and mortality might actually reflect the association between anxiety and mortality.

In conclusion, we found that affective and cognitive symptoms rather than somatic symptoms of depression were associated with long-term mortality and quality of life in patients undergoing chronic hemodialysis. As such, systematic assessment of affective and cognitive symptoms of depression should be undertaken in patients on chronic hemodialysis. Patients with depressive symptoms, as well as those with elevated subthreshold symptoms, should be referred for timely and appropriate intervention.

\section{Methods}

In this prospective cohort study, we followed the patients for more than three years to assess mortality. The ethics committee of the Institutional Research Board at the National Taiwan University Hospital Hsin-Chu Branch approved the proposal before the study. All methods were carried out in accordance with relevant guidelines and 


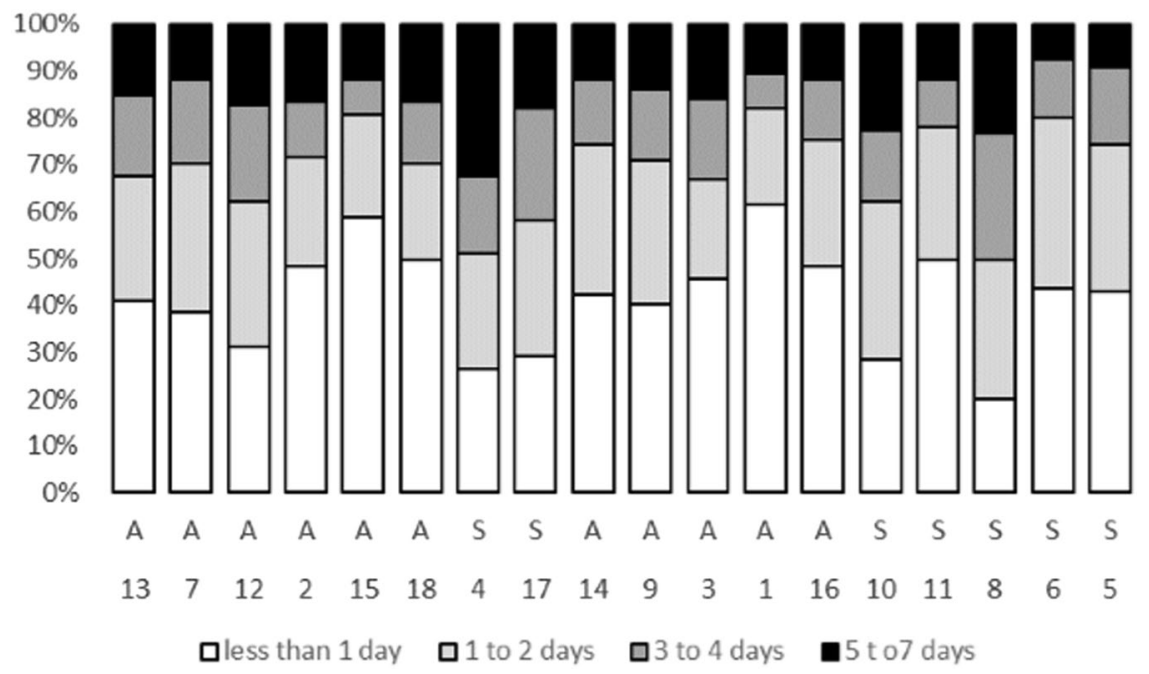

Figure 3. Bar chart of the proportion of the answers to each question of the Taiwan Depression Questionnaire. The order of the questions is based on the information values with the highest on the left. A stands for affective/ cognitive items; $S$ for somatic items. The answers are listed as the number of days that the symptoms are present in the past week.

regulations. Informed consent was obtained from all participants. They were recruited from a hemodialysis facility at a secondary hospital from September 2012 to September 2013. This 819-bed hospital is government-run and located in an urban area of northern Taiwan. The inclusion criteria were (1) having undergoing at least 6 months of hemodialysis treatment, (2) being older than or equal to 20 years of age, and (3) being oriented to person and place and capable of answering the questionnaires. We excluded patients with advanced cancer (stage 4 ) and those with a tracheostomy. A total of 193 patients were eligible, from whom a random sample of 160 patients was chosen. Several patients declined to participate in the study due to privacy concerns. Once the informed consent was obtained, the interview was initiating by asking the patients to report their name, date of birth, age, gender, residential area (county, city and district) and 10-digit identification number, information that was corroborated with the chart by the interviewer. If these basic orientation questions were answered incorrectly, they were excluded from the study. Overall, 151 subjects signed the informed consent forms and completed the interview.

We used the Taiwanese Depression Questionnaire to assess depression by asking subjects the frequency with which they had experienced 18 conditions within the past week. The frequency scale is as follows: 0 (never or seldom; fewer than one day per week), 1 (sometimes; 1-2 days per week), 2 (often; 3-4 days per week) and 3 (very often or always; 5-7 days per week). A total score equal to or higher than 19 had been validated to indicate depression, with $89 \%$ sensitivity and $92 \%$ specificity ${ }^{28}$. This questionnaire adopted a few culturally relevant questions, such as chest tightness (question 6) and bodily discomfort such as headache, dizziness, palpitation, or abdominal distress (question 17) ${ }^{33}$, as depressed Taiwanese patients had been shown to demonstrate predominant somatic manifestations of illness. The TDQ and the BDI were compared for the validity in evaluating depression in patients with chronic pain ${ }^{34}$. Items from both questionnaires are listed for comparison in Table S1 (the English version of the questions were given by the original authors of the $\mathrm{TDQ}^{34}$ ). Questions regarding "past failure," "guilty feelings," "punishment feelings," and "loss of interest in sex" in the BDI were replaced. Question 10 , poor memory or forgetfulness, was classified as a somatic item according to Freudenreich et al. ${ }^{19}$, although it was regarded as a cognitive item in other literatures ${ }^{35}$. Question 7, "I felt uneasy, uncomfortable," was classified as a affective/cognitive item as it asked for being "not in peaceful mind," or having "psychological stress" in Chinese language.

Quality of life was assessed by the World Health Organization Quality of Life assessment questionnaire-brief version (WHOQOL-BREF). This questionnaire is composed of 28 questions that cover four major functions, or domains: physical health, psychological health, social relationships and environment. A higher score indicates a better quality of life. Three registered nurses interviewed the subjects face-to-face to complete the questionnaires. Patient demographic, biochemistry and hemodialysis-related data were also collected.

We used SPSS 20 (IBM, Armonk, New York, United States) to perform the statistical analyses except for the calculation of importance values. The statistician did not participate in data collection, and had no knowledge about which individuals were dead or alive in the final de-identified version of the data. Categorical data were tested using Chi-square test; or Fisher's Exact test if the cell number was less than five. Proportions between two groups were compared with z-tests. Analysis of variance (ANOVA) was used to compare biochemical data among three or more groups, and the Scheffe method was used for the post hoc analysis. We calculated the odds ratio of mortality according to the answers to each question in the Taiwanese Depression Questionnaire using logistic regression analysis with or without adjustments for age and albumin, which are two major determinants of mortality. The hazard ratios of mortality according to the answers to each question in the TDQ were obtained by Cox proportional regression modeling with adjustments for age and albumin. Log-rang test using Kaplan-Meier survival analysis was used to examine whether those who answered differently (4 different answers to each question) 
also have different survival rates. Weights of evidence (WOEs) were calculated using the formula WOE $=$ natural logarithm (\% of survival/\% of death). The information value was the sum of ( $\%$ of survival/\% of death) times WOE. The Mann-Whitney U test was used to compare the order between the affective/cognitive symptoms and the somatic symptoms listed in order by the Spearman rho values. Multiple regression analysis was used to identify independent association factors. Spearman's rank order correlation coefficient, named rho, was calculated to test the correlation between the answers of each TDQ item and the quality of life score. $p$ value less than 0.05 was considered statistically significant.

\section{References}

1. Gu, L. et al. Epidemiology of major depressive disorder in mainland china: a systematic review. PloS one 8, e65356, https://doi. org/10.1371/journal.pone.0065356 (2013).

2. Ohayon, M. M., Priest, R. G., Guilleminault, C. \& Caulet, M. The prevalence of depressive disorders in the United Kingdom. Biological psychiatry 45, 300-307 (1999).

3. Gonzalez, O. et al. Current Depression Among Adults - United States, 2006 and 2008. MMWR Morbidity and Mortality Weekly Report 59, 1229-1235 (2010).

4. Deveney, T. K., Belnap, B. H., Mazumdar, S. \& Rollman, B. L. The prognostic impact and optimal timing of the Patient Health Questionnaire depression screen on 4-year mortality among hospitalized patients with systolic heart failure. General hospital psychiatry 42, 9-14, https://doi.org/10.1016/j.genhosppsych.2016.06.005 (2016).

5. Mitchell, A. J. et al. Prevalence of depression, anxiety, and adjustment disorder in oncological, haematological, and palliative-care settings: a meta-analysis of 94 interview-based studies. The Lancet. Oncology 12, 160-174, https://doi.org/10.1016/S14702045(11)70002-X (2011).

6. Sullivan, M. D. et al. Depression predicts all-cause mortality: epidemiological evaluation from the ACCORD HRQL substudy. Diabetes care 35, 1708-1715, https://doi.org/10.2337/dc11-1791 (2012).

7. Pinquart, M. \& Duberstein, P. R. Depression and cancer mortality: a meta-analysis. Psychological medicine 40, 1797-1810, https:// doi.org/10.1017/S0033291709992285 (2010).

8. Zalai, D., Szeifert, L. \& Novak, M. Psychological distress and depression in patients with chronic kidney disease. Seminars in dialysis 25, 428-438, https://doi.org/10.1111/j.1525-139X.2012.01100.x (2012).

9. Fan, L. et al. Depression and all-cause mortality in hemodialysis patients. American journal of nephrology 40, 12-18, https://doi. org/10.1159/000363539 (2014).

10. Farrokhi, F., Abedi, N., Beyene, J., Kurdyak, P. \& Jassal, S. V. Association between depression and mortality in patients receiving long-term dialysis: a systematic review and meta-analysis. American journal of kidney diseases: the official journal of the National Kidney Foundation 63, 623-635, https://doi.org/10.1053/j.ajkd.2013.08.024 (2014).

11. Wai, L., Richmond, J., Burton, H. \& Lindsay, R. M. Influence of psychosocial factors on survival of home-dialysis patients. Lancet 2, 1155-1156 (1981).

12. Halen, N. V., Cukor, D., Constantiner, M. \& Kimmel, P. L. Depression and mortality in end-stage renal disease. Current psychiatry reports 14, 36-44, https://doi.org/10.1007/s11920-011-0248-5 (2012).

13. Christensen, A. J., Wiebe, J. S., Smith, T. W. \& Turner, C. W. Predictors of survival among hemodialysis patients: effect of perceived family support. Health psychology: official journal of the Division of Health Psychology, American Psychological Association 13, 521-525 (1994)

14. Kimmel, P. L. et al. Psychosocial factors, behavioral compliance and survival in urban hemodialysis patients. Kidney international 54, 245-254, https://doi.org/10.1046/j.1523-1755.1998.00989.x (1998).

15. Cukor, D., Coplan, J., Brown, C., Peterson, R. A. \& Kimmel, P. L. Course of depression and anxiety diagnosis in patients treated with hemodialysis: a 16-month follow-up. Clinical journal of the American Society of Nephrology: CJASN 3, 1752-1758, https://doi. org/10.2215/CJN.01120308 (2008).

16. Wang, H. H., Ho, M. C., Hung, K. Y. \& Cheng, H. T. A single question regarding mobility in the World Health Organization quality of life questionnaire predicts 3-year mortality in patients receiving chronic hemodialysis. Scientific reports 7, 11981, https://doi. org/10.1038/s41598-017-12276-9 (2017).

17. Olagunju, A. T., Campbell, E. A. \& Adeyemi, J. D. Interplay of anxiety and depression with quality of life in endstage renal disease. Psychosomatics 56, 67-77, https://doi.org/10.1016/j.psym.2014.03.006 (2015).

18. Chilcot, J. et al. A confirmatory factor analysis of the Beck Depression Inventory-II in end-stage renal disease patients. Journal of psychosomatic research 71, 148-153, https://doi.org/10.1016/j.jpsychores.2011.02.006 (2011).

19. Freudenreich, O., Kontos, N., Nejad, S. H. \& Gross, A. F. An approach to symptoms at the interface of medicine and psychiatry: pain, insomnia, weight loss and anorexia, fatigue and forgetfulness, and sexual dysfunction. The Medical clinics of North America 94, 1217-1227, xi, https://doi.org/10.1016/j.mcna.2010.08.006 (2010).

20. Cukor, D. et al. Depression and anxiety in urban hemodialysis patients. Clinical journal of the American Society of Nephrology: CJASN 2, 484-490, https://doi.org/10.2215/CJN.00040107 (2007).

21. Chen, W. C. et al. Sleep behavior disorders in a large cohort of chinese (Taiwanese) patients maintained by long-term hemodialysis. American journal of kidney diseases: the official journal of the National Kidney Foundation 48, 277-284, https://doi.org/10.1053/j. ajkd.2006.04.079 (2006)

22. Pierratos, A. \& Hanly, P. J. Sleep disorders over the full range of chronic kidney disease. Blood purification 31, 146-150, https://doi. org/10.1159/000321859 (2011).

23. Hedayati, S. S., Yalamanchili, V. \& Finkelstein, F. O. A practical approach to the treatment of depression in patients with chronic kidney disease and end-stage renal disease. Kidney international 81, 247-255, https://doi.org/10.1038/ki.2011.358 (2012).

24. de Miranda Azevedo, R., Roest, A. M., Hoen, P. W. \& de Jonge, P. Cognitive/affective and somatic/affective symptoms of depression in patients with heart disease and their association with cardiovascular prognosis: a meta-analysis. Psychological medicine 44, 2689-2703, https://doi.org/10.1017/S0033291714000063 (2014).

25. Kimmel, P. L. et al. Multiple measurements of depression predict mortality in a longitudinal study of chronic hemodialysis outpatients. Kidney international 57, 2093-2098, https://doi.org/10.1046/j.1523-1755.2000.00059.x (2000).

26. Peterson, R. A. et al. Depression, perception of illness and mortality in patients with end-stage renal disease. International journal of psychiatry in medicine 21, 343-354 (1991).

27. Kellerman, Q. D., Christensen, A. J., Baldwin, A. S. \& Lawton, W. J. Association between depressive symptoms and mortality risk in chronic kidney disease. Health psychology: official journal of the Division of Health Psychology, American Psychological Association 29, 594-600, https://doi.org/10.1037/a0021235 (2010).

28. Lee, Y., Yang, M. J., Lai, T. J., Chiu, N. M. \& Chau, T. T. Development of the Taiwanese Depression Questionnaire. Chang Gung medical journal 23, 688-694 (2000).

29. Schiffer, A. A. et al. Somatic versus cognitive symptoms of depression as predictors of all-cause mortality and health status in chronic heart failure. The Journal of clinical psychiatry 70, 1667-1673, https://doi.org/10.4088/JCP.08m04609 (2009).

30. Sacks, C. R., Peterson, R. A. \& Kimmel, P. L. Perception of illness and depression in chronic renal disease. American journal of kidney diseases: the official journal of the National Kidney Foundation 15, 31-39 (1990). 
31. Hodes, G. E., Kana, V., Menard, C., Merad, M. \& Russo, S. J. Neuroimmune mechanisms of depression. Nature neuroscience 18, 1386-1393, https://doi.org/10.1038/nn.4113 (2015).

32. Preljevic, V. T. et al. Anxiety and depressive disorders in dialysis patients: association to health-related quality of life and mortality. General hospital psychiatry 35, 619-624, https://doi.org/10.1016/j.genhosppsych.2013.05.006 (2013).

33. Beck, A. T., Ward, C. H., Mendelson, M., Mock, J. \& Erbaugh, J. An inventory for measuring depression. Archives of general psychiatry 4, 561-571 (1961).

34. Lee, Y. et al. Comparing the use of the Taiwanese Depression Questionnaire and Beck Depression Inventory for screening depression in patients with chronic pain. Chang Gung medical journal 31, 369-377 (2008).

35. Austin, M. P., Mitchell, P. \& Goodwin, G. M. Cognitive deficits in depression: possible implications for functional neuropathology. The British journal of psychiatry: the journal of mental science 178, 200-206 (2001).

\section{Author Contributions}

H.T.C. developed the study concept, designed the study, analyzed and interpreted the data and drafted the manuscript; M.C.H. participated in the study design, conducted the interviews, participated in the data interpretation, and revised the manuscript; and K.Y.H. developed the concept, designed the study, interpreted the data, and revised the manuscript.

\section{Additional Information}

Supplementary information accompanies this paper at https://doi.org/10.1038/s41598-018-24267-5.

Competing Interests: The authors declare no competing interests.

Publisher's note: Springer Nature remains neutral with regard to jurisdictional claims in published maps and institutional affiliations.

(c) (i) Open Access This article is licensed under a Creative Commons Attribution 4.0 International License, which permits use, sharing, adaptation, distribution and reproduction in any medium or format, as long as you give appropriate credit to the original author(s) and the source, provide a link to the Creative Commons license, and indicate if changes were made. The images or other third party material in this article are included in the article's Creative Commons license, unless indicated otherwise in a credit line to the material. If material is not included in the article's Creative Commons license and your intended use is not permitted by statutory regulation or exceeds the permitted use, you will need to obtain permission directly from the copyright holder. To view a copy of this license, visit http://creativecommons.org/licenses/by/4.0/.

(C) The Author(s) 2018 